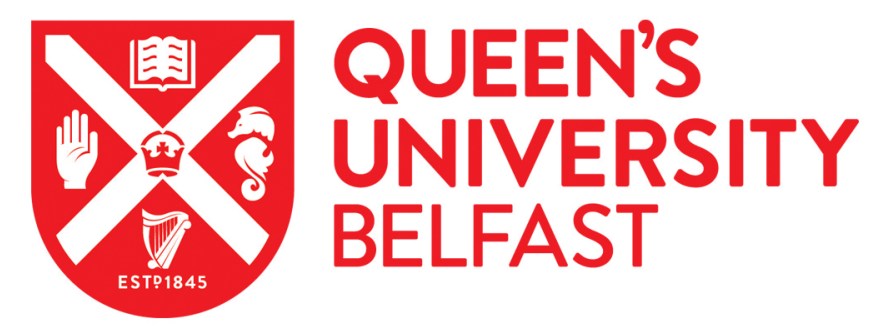

\title{
Tri-Band HIS Backed Spiral Antenna for Wireless LAN Applications
}

Mohamad, S., Cahill, R., \& Fusco, V. (2015). Tri-Band HIS Backed Spiral Antenna for Wireless LAN

Applications. Microwave and Optical Technology Letters, 57(5), 1116-1121. https://doi.org/10.1002/mop.29028

\section{Published in:}

Microwave and Optical Technology Letters

\section{Document Version:}

Peer reviewed version

\section{Queen's University Belfast - Research Portal:}

Link to publication record in Queen's University Belfast Research Portal

\section{Publisher rights \\ Copyright 2015 Wiley Periodicals}

This is the accepted version of the following article: Tri-Band HIS Backed Spiral Antenna for Wireless LAN Applications, which has been published in final form at

http://onlinelibrary.wiley.com/doi/10.1002/mop.29028/abstract;jsessionid=728527E60F070A051E2F11407F134547.f04t03

\section{General rights}

Copyright for the publications made accessible via the Queen's University Belfast Research Portal is retained by the author(s) and / or other copyright owners and it is a condition of accessing these publications that users recognise and abide by the legal requirements associated with these rights.

\section{Take down policy}

The Research Portal is Queen's institutional repository that provides access to Queen's research output. Every effort has been made to ensure that content in the Research Portal does not infringe any person's rights, or applicable UK laws. If you discover content in the Research Portal that you believe breaches copyright or violates any law, please contact openaccess@qub.ac.uk. 


\title{
Tri- band HIS backed spiral antenna for wireless LAN applications
}

\author{
Sarah Mohamad, Robert Cahill and Vincent Fusco \\ The Institute of Electronics, Communications and Information Technology, \\ Queen's University Belfast, Northern Ireland Science Park, Queen's Road, Queen's Island, \\ Belfast, BT3 9DT, Northern Ireland, UK \\ Email: smohamad02@qub.ac.uk
}

Key Words: Spiral antennas, self-complementary antennas, high impedance surfaces, active region, wireless local area network (WLAN) antennas

\section{ABSTRACT}

This study reports the performance of an Archimedean spiral antenna which exhibits unidirectional circularly polarized $(\mathrm{CP})$ radiation patterns with a peak gain $>8 \mathrm{dBic}$ in the lower $(2.4-2.485 \mathrm{GHz})$ and upper (5.15 - 5.35 and $5.725-5.875 \mathrm{GHz}$ ) WLAN frequency bands. The required backlobe suppression and impedance match are obtained by placing a multi resonant high impedance surface (HIS) in close proximity to the radiating aperture. Simulated and measured radiation patterns are shown at the center frequency of all three channels and a comparison of the key performance metrics is made with free space and metal backed antenna arrangements to demonstrate the enhancements which are attributed to the HIS reflector. 


\section{INTRODUCTION}

Circular polarization (CP) antenna technology offers the possibility to remove the challenges associated with traditional linear technologies, including multi-path, mobile connectivity, inclement weather, and absorption, that are collectively responsible for signal degradation in WLAN networks [1]. For this application it is desirable to employ antennas that radiate unidirectional beams to improve security and the efficiency of the propagation channels [2]. The Archimedean spiral is a class of frequency independent antennas which generates circularly polarized bidirectional radiation with equal power in the upper and lower hemisphere [3]. Metal ground planes are often used to suppress backlobe radiation and increase gain when these are placed one quarter wavelength below the radiating aperture. However pattern distortion and impedance mismatch can significantly limit the antenna bandwidth, and although more complex stepped ground plane architectures can be designed to overcome these problems where multiband operation [3] of a spiral is acceptable, this approach is unsuitable for profile miniaturization which is often a major design driver.

Recently a tri-band unidirectional CP antenna consisting of a pair of crossed dipoles backed by a HIS patch array has been designed for WLAN implementation covering the $2.4-2.485 \mathrm{GHz}, 5.15-5.35 \mathrm{GHz}$ and 5.725-5.875 GHz bands [2]. The HIS resonates at 2.4 GHz and is separated from the antenna by $\approx \lambda / 4$ distance at the center frequency of the two upper bands where it behaves as a metal ground plane. The total thickness of the hybrid structure is $17.5 \mathrm{~mm}$.

In this paper we report on an alternative architecture which simplifies the antenna design and significantly reduces the cavity thickness $(8.46 \mathrm{~mm} \approx \lambda / 15$ at $2.44 \mathrm{GHz})$. The profile reduction of $\sim 50 \%$ from $17.5 \mathrm{~mm}$ to $8.46 \mathrm{~mm}$ is achieved by deploying a flat HIS reflector which is designed to resonate in all three WLAN bands when placed below the corresponding active regions of the spiral. Simplification results from using a wideband Archimedean spiral because this removes the need to design individual radiating elements for operation in each of the three WLAN channels, and subsequent numerical optimisation of these in situ above the closely spaced HIS [2]. Simulated return loss, gain, backlobe suppression and axial ratio results are presented over the frequency 
range $2-6 \mathrm{GHz}$ for the spiral antenna in free space, and backed by the HIS and a flat metal plate. These key performance metrics and measured radiation patterns at the center of the WLAN bands are employed to highlight the improvements that are obtained from using the multi resonant HIS reflector.

\section{ANTENNA AND HIS DESIGN}

CST MICROWAVE STUDIO software was used to design the two-arm, four-turn Archimedean spiral antenna (Figure 1(a)) which works in the frequency range 1.6 to $24 \mathrm{GHz}$ and generates predominantly RHCP [4]. The outer and inner diameters are $60 \mathrm{~mm}$ and $4 \mathrm{~mm}$ respectively and the width and spacing between the conductors are both set to $1.65 \mathrm{~mm}$ to realize a constant $188 \Omega$ input impedance self-complementary structure. The numerical model is center fed in anti-phase with equal amplitude signals at two excitation ports separated by a distance of $0.5 \mathrm{~mm}$. In the simulator the periodic array of the HIS, which is composed of patch and square loop nested unit cells, is printed with dimensions of $d_{o}=14 \mathrm{~mm}, d_{p 1}=13.32 \mathrm{~mm}, d_{p 2}=10.8 \mathrm{~mm}$ as shown in Figure 2 (inset), on the surface of a $0.28 \mathrm{~mm}$ thick high permittivity substrate $\left(\varepsilon_{\mathrm{r}}=10\right)$ to reduce the physical size of the unit cells. The periodic array (Figure $1(b)$ ) is separated from the ground plane by a $3 \mathrm{~mm}$ thick foam spacer to form the HIS which was designed to resonate at $2.2 \mathrm{GHz}$ and $5.7 \mathrm{GHz}$ (Figure 2). The same material is employed in the computer model to position the spiral $5 \mathrm{~mm}$ above the surface of the HIS.

\section{RESULTS AND DISCUSSION}

Figure 3 shows the return loss of the antenna computed between $2-6 \mathrm{GHz}$ and in the three individual WLAN bands in free space, and backed by either the HIS or a metal plate placed $8.28 \mathrm{~mm}$ below the spiral to provide the same structure thickness. At low frequencies the impedance match of the latter arrangement is significantly worse than the free space spiral, for example at $2.44 \mathrm{GHz}$ 
the predicted return loss is $6 \mathrm{~dB}$. However an improvement of up to $19 \mathrm{~dB}$ is obtained in the lower (2.44 GHz) WLAN band when the antenna is placed above the HIS, therefore it is evident that the current in the active region of the spiral is less disrupted by the closely spaced $(5 \mathrm{~mm}-\lambda / 25)$ HIS reflector.

A gain increase of $\approx 3 \mathrm{~dB}$ is predicted in the frequency range $3.5-5.9 \mathrm{GHz}$ when the radiating aperture is backed by either a metal ground plane or the HIS, and importantly as illustrated in Figure 4, the latter structure also exhibits a similar improvement in the lower WLAN band where the antenna is impedance matched. The gain increase can largely be attributed to backlobe suppression, and this is quantified in Figure 5 where the front (RHCP) to back (LHCP) ratio of the HIS backed antenna is shown to be $17 \mathrm{~dB}$ and $28-35 \mathrm{~dB}$ higher in the lower and upper WLAN bands respectively. The polarisation purity of the three arrangements is compared in Figure 6 which shows that axial ratio minima occur in two of the WLAN bands close to the resonant frequencies of the HIS. By contrast the crosspolarisation exhibited by the metal backed antenna is significantly higher in the lower WLAN band. In this frequency range the active region is very close to the truncated edge of the spiral, and degradation of the polarization purity is therefore also observed for the HIS backed antenna. To suppress the reflected waves, $560 \Omega$ resistors were employed to terminate the two open ends of the spiral [5]. The numerical predictions are summarized in Table 1 and plotted in Figure $3-6$, where it is shown that the impedance match and axial ratio are more similar to the free space antenna, although in conjunction with these improvements a small decrease in antenna gain is observed, in addition to minor performance differences in the other two WLAN channels.

The HIS (Figure 1(b)) was patterned on a $98 \times 98 \mathrm{~cm}^{2} 0.28 \mathrm{~mm}$ thick Taconic CER-10 substrate with $\varepsilon_{\mathrm{r}}=10$ and $\tan \delta=0.0035$, and the $3 \mathrm{~mm}$ ground plane separation was created by the filling the void with Rhoacell low density foam $\left(\varepsilon_{\mathrm{r}}=1.05\right)$. Time gated bistatic reflection phase measurements were made in an anechoic chamber relative to a $98 \times 98 \mathrm{~cm}^{2}$ metal plate that was placed $30 \mathrm{~mm}$ distance from the aperture of a standard gain horn which covers the frequency range $3-6 \mathrm{GHz}$. The experimental results are depicted in Figure 2. 
The Archimedean spiral was printed on $0.13 \mathrm{~mm}$ thick Taconic TLY-5 glass reinforced PTFE material with $\varepsilon_{\mathrm{r}}=2.2$ and $\tan \delta=0.0009$, and soldered to a $1.1 \mathrm{~mm}$ diameter $50 \Omega$ semi-rigid cable which was formed to replicate the spiral arms (Figure 1(a)). An infinite balun was employed to excite the antenna at the center feed points which are spaced $0.5 \mathrm{~mm}$ apart. This simple feed arrangement can be used to measure the radiation patterns without the need to deploy a transformer to match the spiral impedance to $50 \Omega$. Construction of the sandwich assembly was completed by inserting a $5 \mathrm{~mm}$ thick Rhoacell spacer between the surface of the HIS and the spiral antenna.

Figure 7 shows the normalized predicted and measured co-polar (RHCP) and cross-polar (LHCP) radiation patterns for the antenna in free space and placed above the HIS reflector with a termination resistor soldered to the open end of one arm and a thin strip of microwave absorber placed on the other spiral arm close to the SMA connector. These are plotted at the center frequencies of the WLAN bands, $2.44,5.25$ and $5.8 \mathrm{GHz}$ and for brevity only in the $\phi=0^{\circ}$ (Figure 7) and $\phi=45^{\circ}$ (Figure 8) plane. Figure $7(\mathrm{a})$ and $8(\mathrm{a})$ shows that at all three frequencies the planar spiral exhibits bi-directional radiation with equal gain and opposite polarizations in the upper and lower hemisphere. The backlobe suppression obtained by placing the HIS above the spiral is evident in Figure $7(b)$ and $8(b)$, and for all arrangements the agreement between the measured results and numerical simulations is generally quite good.

\section{CONCLUSIONS}

In this paper we have used a multi-resonant HIS reflector to obtain a high gain unidirectional CP beam at three channels within the operating frequency range of a wideband Archimedean spiral. Although the structure is compact $(\approx \lambda / 15$ at $2.44 \mathrm{GHz})$, the reflector does not significantly degrade the impedance match of the antenna at the operating frequencies which are determined by the HIS resonances. Experimental and numerical results were employed to demonstrate the design methodology for three WLAN channels, and highlight the performance improvement compared to free space and metal backed arrangements. 
ACKNOWLEDGEMENTS

S. Mohamad is supported by a research scholarship from the International Islamic University Malaysia (IIUM). 


\section{REFERENCES}

1. Luxul: X-WAVTM Antennas', http://luxul.com/products/antennas, accessed May 2014

2. S.X. Ta, I. Park, R.W. Ziolkowski, Circularly polarized crossed dipole on an HIS for 2.4/5.2/5.8GHz WLAN applications, IEEE Antennas and Wireless Propag. Lett 12 (2013), 1464-1467.

3. S. Mohamad, R. Cahill, and V. Fusco, Performance enhancement of a wideband spiral antenna using a stepped ground plane, Microwave Opt. Technol Lett 56 (2014), 753-757.

4. S. Mohamad, R. Cahill, and V. Fusco, Selective high impedance surface active region loading of Archimedean spiral antenna, IEEE Antennas and Wireless Propag Lett 13 (2014), 810-813.

5. P.A. Ramsdale and P.W. Crampton, Properties of 2-arm conical equiangular spiral antenna over extended bandwidth, Microwaves, Optics and Antennas, IEE Proceedings H 128 (1981), 311-316. 


\section{FIGURE CAPTIONS}

Figure 1. Photograph of (a) Archimedean spiral antenna, and (b) HIS.

Figure 2. Simulated and measured phase of multi-resonant HIS, and (inset) unit cell dimensions of HIS; $d_{o}=14 \mathrm{~mm}, d_{p 1}=13.32 \mathrm{~mm}, d_{p 2}=10.8 \mathrm{~mm}$

Figure 3. Simulated return loss of free space, metal backed and HIS backed spiral antenna with and without $560 \Omega$ termination resistors at lower $(2.4-2.485 \mathrm{GHz})$ and upper (5.15-5.35 and 5.727-5.875 GHz) WLAN frequency bands (ref: $188 \Omega$ ).

Figure 4. Simulated realized gain $(\mathrm{dB})$ of free space, metal backed, and HIS backed spiral antenna with and without $560 \Omega$ termination resistors.

Figure 5. Simulated front-to-back ratio (dB) of free space, metal backed, and HIS backed spiral antenna with and without $560 \Omega$ termination resistors.

Figure 6. Simulated boresight axial ratio (dB) of free space, metal backed, and HIS backed spiral antenna with and without $560 \Omega$ termination resistors.

Figure 7. Normalized simulated and measured co-polar (RHCP) and cross-polar (LHCP) radiation patterns of the spiral antenna at $\phi=0^{\circ}(a)$ in free space, and (b) with $560 \Omega$ resistors and HIS at frequencies $2.44,5.25$ and $5.8 \mathrm{GHz}$.

Figure 8. Normalized simulated and measured co-polar (RHCP) and cross-polar (LHCP) radiation patterns of the spiral antenna at $\phi=45^{\circ}$ (a) in free space, and (b) with $560 \Omega$ resistors and HIS at frequencies $2.44,5.25$ and $5.8 \mathrm{GHz}$. 


\section{$\underline{\text { TABLE CAPTIONS }}$}

Table 1. Co-polar realized gain, $F / B$ ratio and axial ratio at boresight $(\mathrm{dB})$ of spiral antenna in free space and with HIS at 2.44, 5.25 and $5.8 \mathrm{GHz}$. (Results for resistor values of $560 \Omega$ are shown in brackets).
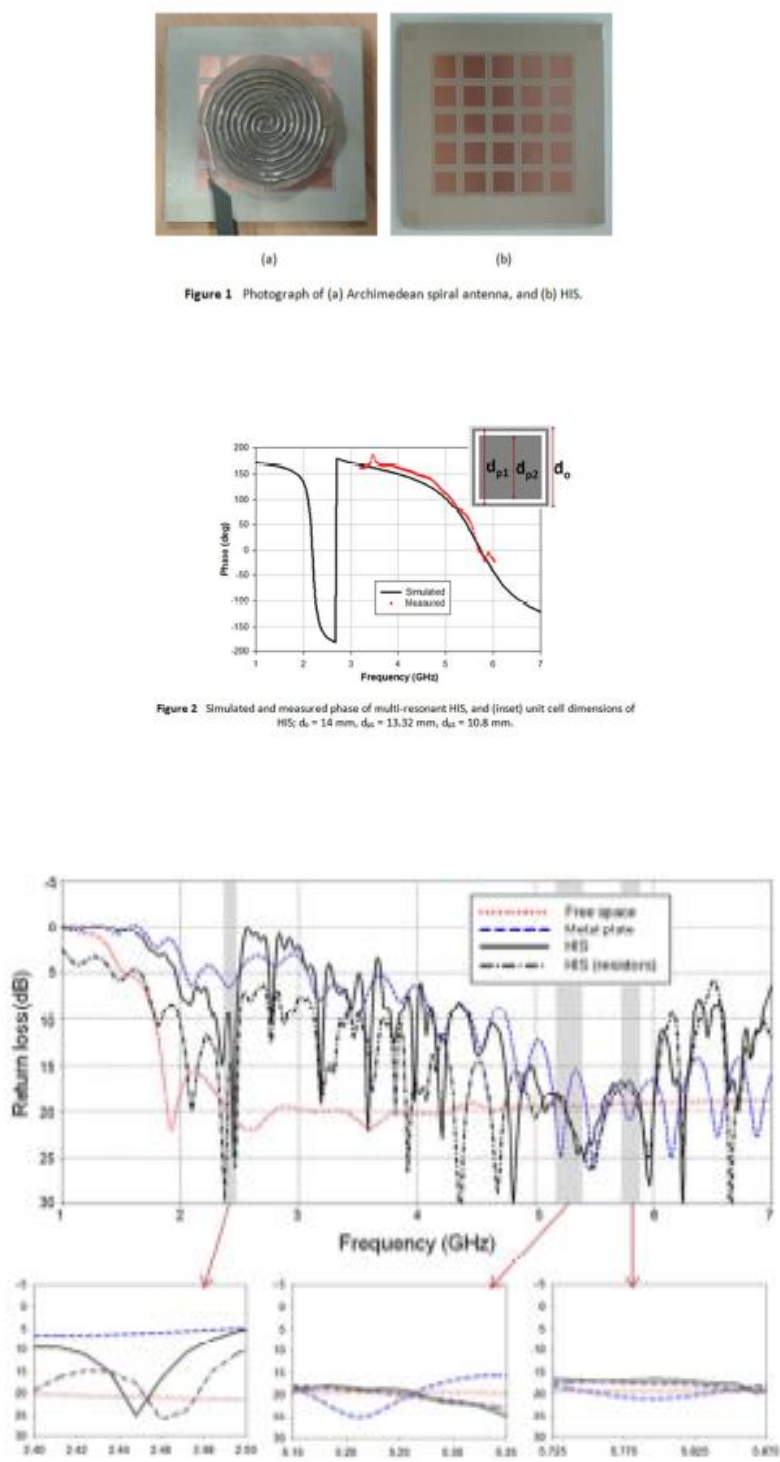

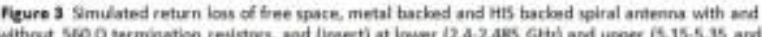

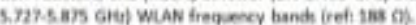




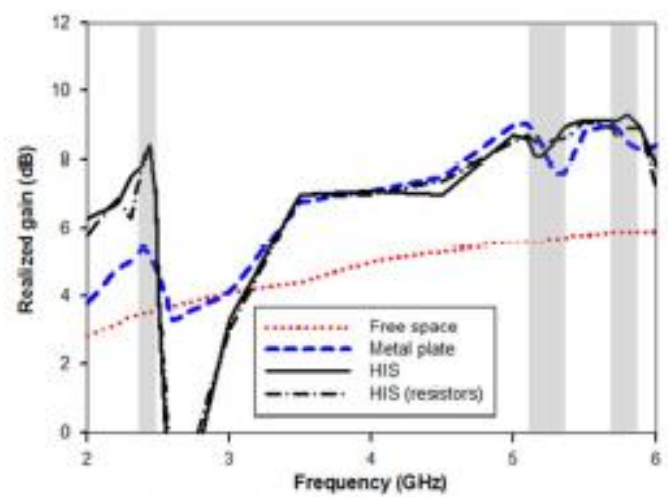

Figure 4 Simulatod realined gain (dB) of tree space, metal backed, and Hit backed spiral anteonn with and without 560 a termination resistors.

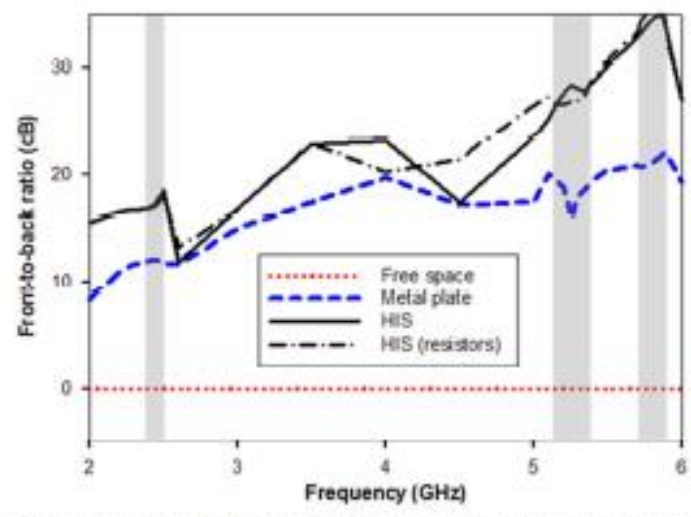

figure 5 simulned front to- backratio (dili) of freespace, metal backed, and His backed spiral antenna with and without $\$ 60$ o termination resistors

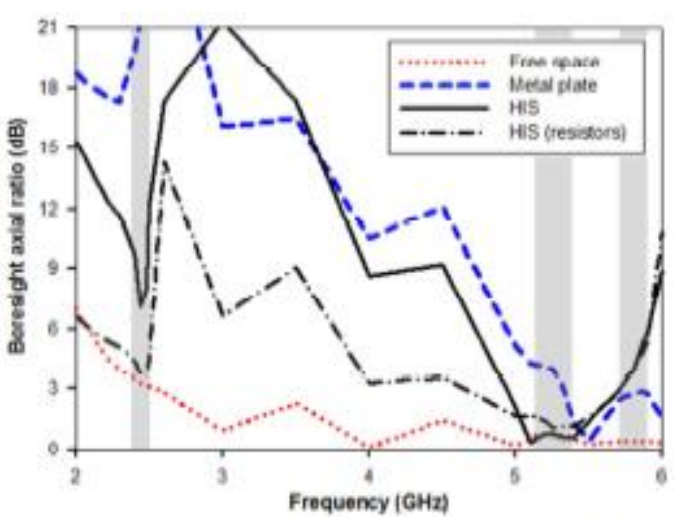

Figure 6 Simulated boresight axial ratio(dis) of free space, metal backed, and hes backed spiral antenna wath and without 560 o termination resistors 


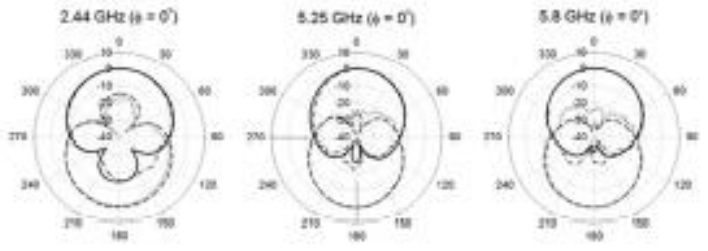

(2) Free seece

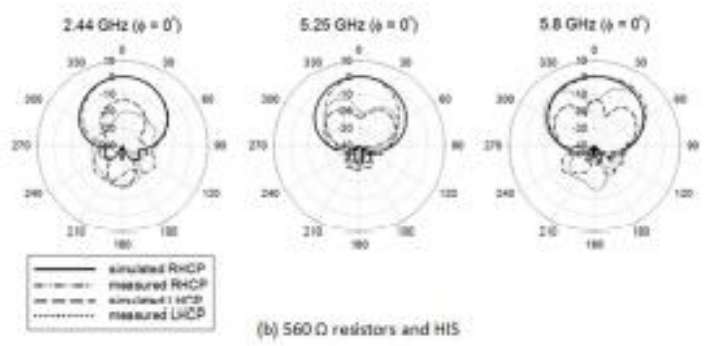

Fieure 7 Nonmolized simulated and measured copolar (AHCP) and cross-polar (LHCP) radiatioe

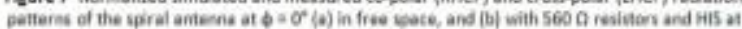
frequencies 2.44 .5 .25 and $5.86 \mathrm{Gt}$.

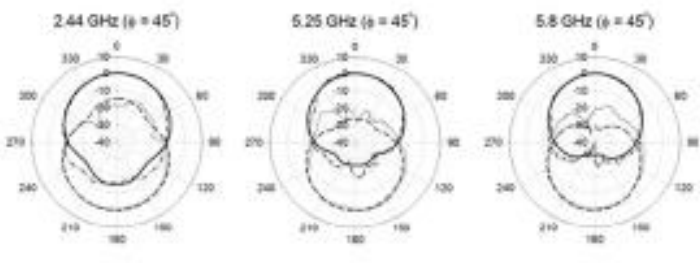

(a) Free space

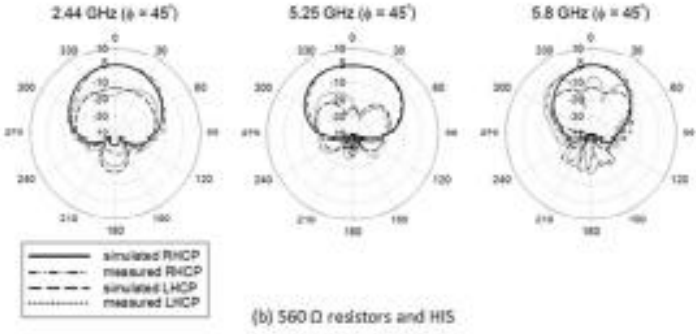

Fegure 8 Normalised simulated and messured co-polar (AHCP) and cross polar [UHCP] radiation

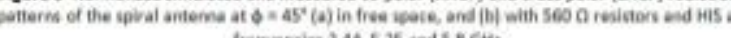
treipumecies 2.44 .5 .25 and S.8 G.t4. 